West German ecology

\section{Ozone named as culprit}

GERMAN forests, long admired as examples of sustained high yields through careful management, have in recent years suffered degeneration that has become a matter of national concern. Since 1976 , highly visible damage to spruce (Picea abies) has been seen in the Black Forest and in Bavaria. Similar symptoms have occurred in fir (Abies alba) and last year damage was found elsewhere in West Germany and in other species, including broadleaves.

Typically, with fir, the needles become yellowish and fall off. Those below the crown are first affected, causing the tree to assume a "stork's nest" appearance. Damage is most frequent to trees exposed to sunlight and wind on south-west slopes more than $800 \mathrm{~m}$ above sea level.

A widely held view is that the yellowing and die-back are effects of "acid rain". Dr J. Bauch of Hamburg University has proposed that the increased acidity of the soil inhibits rootlet and mycorrhiza development.

In September 1982, however, the Pollution Control Establishment in the Land of Nordrhein-Westfalia began an intensive investigation. An interim report published at the end of December concluded that the real culprit is ozone, formed by the action of light on oxides of nitrogen in the atmosphere. An impressive amount of circumstantial evidence is presented, such as the appearance of symptoms after the sunny summer of 1976 and the correlation of damage with ozone content in the atmosphere rather than with the acidity of the precipitation. And in laboratory tests, the difference in the effect of rain of $p \mathrm{H} 4.5$ and 3 was slight, but exposure of spruce to ozone at $100-400$ $\mu \mathrm{g} \mathrm{m}^{-3}$ for 3-4 weeks produced chlorotic mottling. The lichens Hypogymnia physodes and Pseudoverna furfuracea appear to be more sensitive to acid rain but less so to ozone than trees.

The proportion of affected trees varies considerably. In parts of Bavaria bordering

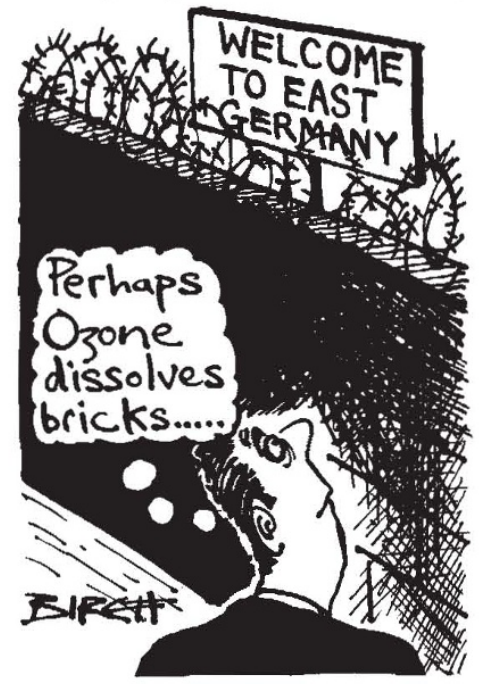

Czechoslovakia and East Germany (GDR), more than 40 per cent of the trees are damaged, and nowhere in Bavaria is the proportion less than 10 per cent. It was estimated last year that 7.7 per cent of trees in all West German forests had some degree of damage.

So, inevitably, pollution control has become a political issue; indeed, it was a contributory factor in the break-up of the former coalition SPD-FDP government

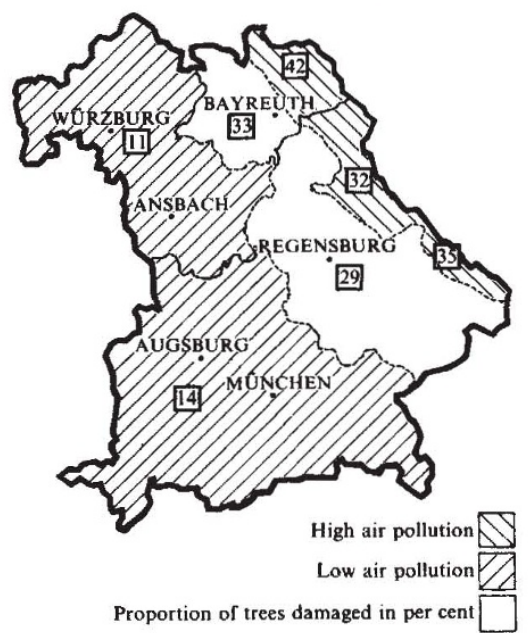

Damage to forests in Bavaria in 1981

last October. Herr Baum, then FDP interior minister, had been pressing for more stringent control of industrial emissions, but was opposed by Herr Lambsdorff, finance minister, also of FDP. Lambsdorff has now found a place in the new CDU-FDP coalition where he is supported by Herr Franz-Josef Strauss, the Bavarian CSU leader, who has tried to play down the seriousness of the situation despite the signs of damage in his own Land.

In reducing pollutant levels, West Germany is not its own master. About half the pollution comes from outside, chiefly from East Germany, where about 270 million tonnes of brown coal (70 per cent of total energy) was burned in 1982, and France. West Germany itself is a substantial exporter of pollution, chiefly industrial waste gases given out by tall chimneys, but by 1990 most power stations should be equipped with gas scrubbers.

Internal factors have inhibited the development of an overall environmental protection policy. There is no federal environment ministry, a situation which SPD is likely to remedy if returned to power in the March elections, and even some of the Länder divide responsibility between the interior and agriculture departments. The fact that the LIS, in central-northern Germany, recently produced a report largely concerned with damage to forests in the southern Lander of Bavaria and Baden-Würtemburg, shows that inter-Land barriers are being overcome.
Infrared astronomy Satellite launch
of telescope

If all went well, the Infrared Astronomical Satellite (IRAS) will have been launched on a Thor-Delta rocket from Vandenberg Air Force Base in California at 0220 GMT on Wednesday, 26 January. Once launched, IRAS will embark on the first sky survey at infrared wavelengths from outside the Earth's atmosphere.

The experiment is a joint venture by the United States, which supplied the main infrared telescope and the launch vehicle, the United Kingdom, which will be controlling the satellite and receiving and processing raw data at the RutherfordAppleton Laboratory in Oxfordshire and the Netherlands, which supplied the satellite vehicle and cooling system, together with a subsidiary infrared telescope.

The detectors are housed in a cooling vessel whose hollow walls are filled with liquid helium at $2 \mathrm{~K}$, minimizing thermal infrared noise from the detectors' environment. Previous space-borne infrared detectors have been cooled to about $12 \mathrm{~K}$. IRAS will provide about a ninety-fold increase in signal-to-noise ratio over the earlier experiments.

Unfortunately, the lifetime of the liquid helium is limited due to vaporization, so IRAS is likely to be useful for no longer than seven months. For almost all of that time the main telescope will be devoted to a sky survey at four wavelengths: 8.5 to 15 , 19 to 30,40 to 80 and 83 to 119 micrometres. The additional experiment supplied by the Netherlands will be used to examine particular regions of interest with greater spatial and spectral resolution than can be achieved by the survey telescope. But the survey will be interrupted only if particularly interesting objects are observed. Data will be received twice daily at the Rutherford-Appleton Laboratory and, after preliminary processing, will be distributed to observatories around the world*.

Infrared astronomy from the ground is hindered by the presence of absorbing gases (water vapour, for instance) in the atmosphere. However, peering through "windows" in the absorption spectrum over the past few decades, astronomers have detected objects such as very young and very old stars whose main signatures are at infrared wavelengths. Infrared waves can also emanate from regions shielded by gas at optical wavelengths, such as the centre of our Galaxy. As well as such expected infrared sources (about a million in all), astronomers are anticipating discoveries of new types of objects.

Philip Campbel

*A summary of the data will be published in Nature every two weeks during the lifetime of the satellite. 